\title{
The influence of shift work on health behaviors and self-reported health status of nurses
}

\author{
Wpływ pracy zmianowej na zachowania zdrowotne i samoocenę zdrowia pielęgniarek
}

\section{Anna Kędzierska' ${ }^{1}$ Ewelina Czerepaniak ${ }^{3}$, Marzanna Stanisławska², Sylwia Wieder-Huszla ${ }^{1}$, Jolanta Wesołowska ${ }^{4}$, Anna Jurczak}

\author{
'Department of Clinical Nursing, Pomeranian Medical University in Szczecin/ \\ Zakład Pielęgniarstwa Specjalistycznego, Pomorski Uniwersytet Medyczny w Szczecinie \\ 2Department of Nursing, Pomeranian Medical University in Szczecin/ \\ Zakład Pielęgniarstwa Pomorskiego Uniwersytetu Medycznego w Szczecinie \\ ${ }^{3}$ Students' Scientific Circle at Department of Nursing, Pomeranian Medical University in Szczecin/ \\ Koło Naukowe Zakładu Pielęgniarstwa, Pomorski Uniwersytet Medyczny w Szczecinie \\ ${ }^{4}$ Department of Esthetic Dermatology/Zakład Dermatologii Estetycznej
}

ORCID:

Anna Kędzierska: 0000-0002-5772-2536 Marzanna Stanisławska: 0000-0002-4867-9732 Sylwia Wieder-Huszla: 0000-0002-6084-5780 Anna Jurczak: 0000-0003-1935-5285

CORRESPONDING AUTHOR/AUTOR DO KORESPONDENCJI:

Anna Kędzierska

Zakład Pielęgniarstwa Specjalistycznego PUM ul. Żołnierska 48, 71-210 Szczecin e-mail: anna.kedzierska@pum.edu.pl

STRESZCZENIE

Słowa kluczowe:

ABSTRACT

\section{WPAYW PRACY ZMIANOWEJ NA ZACHOWANIA ZDROWOTNE I SAMOOCENE ZDROWIA PIELEGNIAREK}

Wprowadzenie. Warunki pracy związane z wykonywaniem czynności zawodowych wiążą się niejednokrotnie z narażeniem jednostki na działanie czynników wpływających negatywnie na jej stan zdrowia. Zawód pielęgniarki/pielęgniarza ze względu na specyficzny charakter uwarunkowany jest wieloma zagrożeniami zawodowymi wynikającymi zarówno z czynników szkodliwych i niebezpiecznych, jak i systemu pracy.

Cel pracy. Celem badań była analiza wpływu pracy zmianowej na samoocenę zdrowia oraz zachowania zdrowotne pielęgniarek. Materiał i metody. Badanie przeprowadzono wśród 200 pielęgniarek w trzech szczecińskich szpitalach: SPSK Nr 1, SPSK Nr 2 i SPWSZ. Narzędzie badawcze stanowił kwestionariusz IZZ - Inwentarz Zachowań Zdrowotnych autorstwa Z. Juczyńskiego oraz ankieta autorska obejmująca dane socjodemograficzne i medyczne.

Wyniki. Samoocena zdrowia badanych pielęgniarek plasowała się na wysokim poziomie, gdyż $76 \%$ z nich określiło swój stan zdrowia jako dobry lub bardzo dobry. Większość badanych, tj. 54\% charakteryzowała się niskim nasileniem zachowań zdrowotnych. Najczęściej wskazywanymi przez pielęgniarki dolegliwościami związanymi z wykonywaną pracą były: zaburzenia snu (55\%), napady bólów głowy po powrocie z pracy (55\%), rozdrażnienie po powrocie z pracy (83\%), problemy skórne (28\%), bóle kręgosłupa (76\%), ból/zmęczenie nóg (84\%), zaburzenia łaknienia (14\%).

Wnioski. 1. System pracy znacząco wpływa na poziom samooceny zdrowia badanej grupy pielęgniarek. 2. Personel pielęgniarski pracujący w dziennym systemie pracy cechował się wyższym poziomem zachowań zdrowotnych w porównaniu do pielęgniarek pracujących w systemie zmianowym. 3. Praca w systemie zmianowym korelowała z częstszym wystąpieniem zaburzeń odżywiania w porównaniu do zatrudnienia w systemie dziennym.

zachowania zdrowotne, styl życia, personel pielęgniarski

\section{IHE INFLUENCE OF SHIFT WORK ON HEALTH BEHAVIORS AND SELF-REPORTED HEALTH STATUS OF NURSES}

Introduction. Working conditions often involve employees' exposure to factors having adverse effects on their health. Due to its nature, the nursing profession entails numerous risks, associated both with harmful factors and a work system itself.

Aim. Aim of this study was to analyze the influence of a shift work system on self-reported health status and health behaviors of nurses.

Material and methods. The study included 200 nurses employed in three Szczecin hospitals: the Independent Public Clinical Hospital no. 1, Pomeranian Medical University in Szczecin, Independent Public Clinical Hospital no. 2, Pomeranian Medical University in Szczecin, and Independent Public Voivodeship Integrated Hospital. The research instruments were the Health Behavior Inventory 
(HBI) developed by Zygfryd Juczyński, and a self-developed questionnaire concerning sociodemographic and medical data.

Results. When it comes to $76 \%$ of the nurses, they described their health status as good or very good. The majority of the respondents (54\%) displayed a low level of health behaviors. The most common work-related complaints were sleep disorders (55\%), headaches after return home from work (55\%), irritation after return home from work (83\%), skin problems (28\%), back pains (76\%), leg pain/ fatigue (84\%), and eating disorders (14\%).

Conclusions. 1. A work system had substantial effect on self-reported health status of the studied group of nurses. 2 . The nurses working day shifts displayed a higher level of health behaviors than their counterparts working in a shift system. 3. A day/night shift work pattern correlated with a higher incidence of eating disorders.

Key words: health behaviors, lifestyle, nursing staff

\section{INTRODUCTION}

Considering their nature, medical professions entail exposure to negative determinants of human health, such as biological (pathogenic microorganisms), physical (electromagnetic field, ionizing, laser, ultraviolet radiation), chemical (anesthetic gases, disinfectants, cytostatic drugs, latex), ergonomic (access to specialist equipment, excessive physical effort, bad workplace organization, ignoring alarming symptoms by workers), and psychological factors (stress, working conditions, types of tasks, institutional resources having an impact on the comfort of work), as well as the influence of microclimate on the body (cold or hot microclimate, noise, vibrations) [1]. All these aspects may have negative consequences for employees' health. The necessity of providing hospitalized patients with continuous care requires shift work. A 12-hour rotating day/night shift pattern is a basic form of nurses' employment [2]. The literature provides numerous reports confirming adverse effects of shift work on a human body. These effects include the increased risk of cardiovascular disease, digestive disorders, sleep problems, neuropsychiatric disorders, and pain symptoms [3-17].

\section{AIM}

The aim of this study was to analyze the influence of shift work on nurses' self-reported health status and health behaviors.

\section{MATERIALS AND METHODS}

The study sample included 200 nurses employed in three Szczecin healthcare centers: the Independent Public Clinical Hospital no. 1, Pomeranian Medical University in Szczecin, Independent Public Clinical Hospital no. 2, Pomeranian Medical University in Szczecin, and Independent Public Voivodeship Integrated Hospital. The nurses included in this study were employed in intensive care units, cardiac, surgical, gastroenterology, neurology, gynecology, pediatric, cancer, nephrology, and hematology wards, operating blocks, emergency rooms, and admission rooms.

The study was survey-based and conducted using a self-developed questionnaire concerning sociodemographic and medical data, and a standardized questionnaire for measuring health behaviors - the Health Behavior Inventory (HBI) developed by Zygfryd Juczyński [17].
The latter instrument includes 24 statements describing four health categories: good eating habits, health practices, preventive behaviors, and positive mental attitudes. Good eating habits mean consuming various nutritious foods. Preventive behaviors include searching for information on health and disease and following the doctor's instructions. Health practices are associated with recreation, sleep, and physical activity. Positive mental attitude refers to avoiding stress and strong emotions. The result for health behaviors may range from 24 to 120 points - the higher the result, the higher the level of health behaviors. The data were subjected to statistical analysis performed using Pearson's $r$ correlation coefficient, the Fisher-Snedecor analysis of variance, and Pearson's chi-square test. Statistical interpretation of the data was performed using IBM SPSS (version 22).

\section{RESULTS}

A vast majority of the respondents (97\%) were women, over half of the surveyed (55\%) were aged between 30 and 60 years, $71.1 \%$ worked 12 -hour shifts. When it comes to $63 \%$ of the studied nurses, they had normal weight, $34 \%$ had BMI beyond a normal range, and only $3 \%$ were underweight.

The majority of the respondents (93\%) were physically active, only $7 \%$ declared themselves not to practice sports or any other physical activity. Risk behaviors displayed by the respondents were alcohol consumption (85\%) and smoking (61\%).

The studied nurses had a high self-reported health status - as many as $76 \%$ described their health status as good and very good. The causes of health problems mentioned by the respondents were: stress (35\%), accidents (15\%), work (11\%), diet (7\%) and others (9\%).

As many as $36 \%$ of the nursing staff complained of work-related health problems, the most common of which were sleep disorders (55\%), headaches after return home from work (55\%), irritation after return home from work (83\%), skin problems (28\%), back pains (76\%), leg pain/ fatigue (84\%), and eating disorders (14\%).

The day-shift workers assessed their health considerably better than those doing rotating shift work $(\mathrm{p}<0.0001)$ (Tab. 1.). Self-reported health status depended also on the place of employment - the highest health status was observed in the nurses working in cancer and hematology wards, and admission rooms, and the lowest in those 


\section{The influence of shift work on health behaviors and self-reported health status of nurses}

Tab. 1. The influence of a work system on nurses' self-reported health status

\begin{tabular}{|c|c|c|c|c|c|c|c|c|c|c|}
\hline \multirow{3}{*}{ Work system } & \multicolumn{8}{|c|}{ Self-reported health status } & \multirow{3}{*}{$\lambda^{2}$} & \multirow{3}{*}{ p } \\
\hline & \multicolumn{2}{|c|}{$\begin{array}{l}\text { very } \\
\text { good }\end{array}$} & \multicolumn{2}{|c|}{ good } & \multicolumn{2}{|c|}{ normal } & \multicolumn{2}{|c|}{ poor } & & \\
\hline & $\mathbf{n}$ & $\%$ & $\mathbf{n}$ & $\%$ & $\mathbf{n}$ & $\%$ & $\mathbf{n}$ & $\%$ & & \\
\hline Day shifts & 44 & 76 & 12 & 21 & 2 & 3 & 0 & 0 & 90.97 & 0.000 \\
\hline Day/night shifts & 13 & 9 & 84 & 59 & 44 & 31 & 1 & 1 & 90.97 & 0.000 \\
\hline
\end{tabular}

$n$ - number of participants, $\lambda^{2}$ - Pearson's Chi-square test, $p$ - level of significance

Tab. 2. Correlation coefficient between the level of health behaviors and place of work

\begin{tabular}{|c|c|c|c|c|c|}
\hline Ward & n & $M \pm S D$ & Min - Max & $\mathbf{F}$ & $\mathbf{p}$ \\
\hline Admission room & 10 & $5.70-2.35$ & $1-8$ & \multirow{13}{*}{2.75} & \multirow{13}{*}{0.002} \\
\hline Gastroenterology & 14 & $5.35-2.43$ & $2-10$ & & \\
\hline Pediatric & 10 & $5.30-1.70$ & $2-7$ & & \\
\hline Cancer & 10 & $5.10-2.42$ & $1-8$ & & \\
\hline Hematology & 6 & $5.00-1.54$ & $2-6$ & & \\
\hline Emergency room & 13 & $4.76-2.16$ & $1-8$ & & \\
\hline Operating block & 12 & $4.75-2.05$ & $1-7$ & & \\
\hline Neurology & 11 & $4.63-2.46$ & $1-8$ & & \\
\hline Cardiac & 19 & $4.52-2.09$ & $1-8$ & & \\
\hline Gynecology & 11 & $4.36-2.11$ & $2-7$ & & \\
\hline Nephrology & 9 & $4.33-2.00$ & $2-8$ & & \\
\hline Surgical & 18 & $3.88-2.32$ & $2-10$ & & \\
\hline Intensive care units & 57 & $3.21-1.48$ & $1-7$ & & \\
\hline
\end{tabular}

$n$ - number of participants, $M$ - mean, SD - standard deviation, Max - maximum, Min - minimum

$\mathrm{F}$ - Fisher-Snedecor's test, $\mathrm{p}$ - level of significance
Tab. 3. The correlation coefficient between the level of health behaviors, BMl and the work system

\begin{tabular}{|c|c|c|c|c|c|c|}
\hline $\begin{array}{c}\text { Categories of } \\
\text { health behaviors } \\
\text { according to the } \\
\text { HBI }\end{array}$ & $\begin{array}{c}\text { Work } \\
\text { system }\end{array}$ & n & $M \pm S D$ & Min - Max & $\mathbf{F}$ & p \\
\hline \multirow{3}{*}{$\begin{array}{l}\text { Good eating } \\
\text { habits }\end{array}$} & Day shifts & 58 & $3.88-0.42$ & $2.50-4.83$ & \multirow{3}{*}{55.40} & \multirow{3}{*}{0.0001} \\
\hline & $\begin{array}{c}\text { Day/night } \\
\text { shifts }\end{array}$ & 142 & $3.12-0.74$ & $1.67-4.67$ & & \\
\hline & Total & 200 & $3.34-0.74$ & $1.67-4.83$ & & \\
\hline \multirow{3}{*}{$\begin{array}{l}\text { Preventive } \\
\text { behaviors }\end{array}$} & Day shifts & 58 & $3.42-0.35$ & $2.33-4.83$ & \multirow{3}{*}{36.64} & \multirow{3}{*}{0.0001} \\
\hline & $\begin{array}{c}\text { Day/night } \\
\text { shifts }\end{array}$ & 142 & $3.83-0.71$ & $1.17-5.00$ & & \\
\hline & Total & 200 & $3.00-0.68$ & $1.17-5.00$ & & \\
\hline \multirow{3}{*}{$\begin{array}{l}\text { Positive mental } \\
\text { attitudes }\end{array}$} & Day shifts & 58 & $3.99-0.50$ & $2.33-4.83$ & \multirow{3}{*}{82.55} & \multirow{3}{*}{0.0001} \\
\hline & $\begin{array}{c}\text { Day/night } \\
\text { shifts }\end{array}$ & 142 & $3.08-0.70$ & $1.83-5.00$ & & \\
\hline & Total & 200 & $3.35-0.77$ & $1.83-5.00$ & & \\
\hline \multirow{3}{*}{ Health practices } & Day shifts & 58 & $4.02-0.38$ & $3.00-4.83$ & \multirow{3}{*}{312.36} & \multirow{3}{*}{0.0001} \\
\hline & \begin{tabular}{|c|} 
Day/night \\
shifts
\end{tabular} & 142 & $2.42-0.64$ & $1.17-4.67$ & & \\
\hline & Total & 200 & $2.88-0.93$ & $1.17-4.83$ & & \\
\hline \multirow{3}{*}{$\begin{array}{l}\text { Level of health } \\
\text { behaviors (HBI) }\end{array}$} & Day shifts & 58 & $6.55-1.01$ & $5-10$ & \multirow{3}{*}{171.38} & \multirow{3}{*}{0.0001} \\
\hline & $\begin{array}{c}\text { Day/night } \\
\text { shifts }\end{array}$ & 142 & $3.39-1.72$ & $1-10$ & & \\
\hline & Total & 200 & 4.31-2.11 & $1-10$ & & \\
\hline \multirow{3}{*}{ BMI } & Day shifts & 58 & $23.01-4.21$ & 17.91-39.18 & \multirow{3}{*}{171.38} & \multirow{3}{*}{0.0001} \\
\hline & $\begin{array}{c}\text { Day/night } \\
\text { shifts }\end{array}$ & 142 & $24.51-4.30$ & 18.82-39.18 & & \\
\hline & Total & 200 & $24.07-4.31$ & $17.91-39.18$ & & \\
\hline
\end{tabular}

$n$ - number of participants, $M$ - mean, SD - standard deviation, Max - maximum, Min - minimum, $\mathrm{F}$ - Fisher-Snedecor's test, $\mathrm{p}$ - level of significance, $\mathrm{HBI}$ - Health Behavior Inventory

Tab. 4. The influence of a work system on the incidence of risk behavior/health complaints among nurses

\begin{tabular}{|c|c|c|c|c|c|c|c|c|c|c|c|c|c|}
\hline \multirow{3}{*}{$\begin{array}{l}\text { Health Behaviors } \\
\text { /Health complaints }\end{array}$} & \multirow{3}{*}{ Work system } & \multicolumn{10}{|c|}{ Incidence of risk behaviors/complaints } & \multirow{3}{*}{$\lambda^{2}$} & \multirow{3}{*}{$\mathbf{p}$} \\
\hline & & \multicolumn{2}{|c|}{ none } & \multicolumn{2}{|c|}{$\begin{array}{l}\text { less than } \\
\text { once a week }\end{array}$} & \multicolumn{2}{|c|}{ once a week } & \multicolumn{2}{|c|}{$\begin{array}{l}\text { up to three } \\
\text { times a week }\end{array}$} & \multicolumn{2}{|c|}{$\begin{array}{c}\text { more than three } \\
\text { times a week }\end{array}$} & & \\
\hline & & $\mathbf{n}$ & $\%$ & $\mathbf{n}$ & $\%$ & $\mathbf{n}$ & $\%$ & n & $\%$ & n & $\%$ & & \\
\hline \multirow{2}{*}{ Alcohol consumption } & Day shifts & 27 & 19 & 99 & 70 & 9 & 6 & 6 & 4 & 2 & 1 & \multirow{2}{*}{56.33} & \multirow{2}{*}{0.000} \\
\hline & Day/night shifts & 2 & 3 & 26 & 45 & 29 & 50 & 1 & 2 & 0 & 0 & & \\
\hline & & \multicolumn{2}{|c|}{ never } & \multicolumn{2}{|c|}{ seldom } & \multicolumn{2}{|c|}{ sometimes } & \multicolumn{2}{|c|}{ quite often } & \multicolumn{2}{|c|}{ very often } & $\lambda^{2}$ & $\mathbf{p}$ \\
\hline \multirow{2}{*}{ Smoking } & Day shifts & 30 & 52 & 24 & 41 & 3 & 5 & 1 & 2 & 0 & 0 & \multirow{2}{*}{53.58} & \multirow{10}{*}{0.000} \\
\hline & Day/night shifts & 48 & 34 & 12 & 8 & 28 & 20 & 39 & 27 & 15 & 11 & & \\
\hline \multirow{2}{*}{ Sleeping problems } & Day shifts & 45 & 78 & 10 & 17 & 3 & 5 & 0 & 0 & 0 & 0 & \multirow{2}{*}{37.67} & \\
\hline & Day/night shifts & 45 & 32 & 44 & 31 & 37 & 26 & 15 & 11 & 1 & 1 & & \\
\hline \multirow{2}{*}{ Headaches } & Day shifts & 50 & 86 & 6 & 10 & 1 & 2 & 1 & 2 & 0 & 0 & \multirow{2}{*}{56.17} & \\
\hline & Day/night shifts & 41 & 29 & 37 & 26 & 47 & 33 & 16 & 11 & 1 & 1 & & \\
\hline \multirow{2}{*}{ Back pains } & Day shifts & 37 & 64 & 10 & 17 & 9 & 16 & 2 & 3 & 0 & 0 & \multirow{2}{*}{76.79} & \\
\hline & Day/night shifts & 11 & 8 & 27 & 19 & 58 & 41 & 18 & 13 & 28 & 20 & & \\
\hline \multirow{2}{*}{ Leg pain/fatigue } & Day shifts & 22 & 38 & 27 & 47 & 8 & 14 & 0 & 0 & 1 & 2 & \multirow{2}{*}{69.80} & \\
\hline & Day/night shifts & 10 & 7 & 21 & 15 & 68 & 48 & 18 & 13 & 25 & 18 & & \\
\hline & & \multicolumn{6}{|c|}{ Yes } & \multicolumn{4}{|c|}{ No } & \multirow{2}{*}{$\lambda^{2}$} & \\
\hline & & & $\mathbf{n}$ & & & $\%$ & & & & & & & $\mathbf{p}$ \\
\hline & Day shifts & & 7 & & & 12 & & & & & & 3 & 0000 \\
\hline 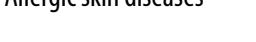 & Day/night shifts & & 49 & & & 35 & & & & & & 10.20 & 0.000 \\
\hline
\end{tabular}


employed in intensive care units and gastroenterology wards (Tab. 2.).

Analysis of the HBI results revealed that the majority of the respondents (54\%) displayed a low level of health behaviors. When it comes to $28 \%$ of the respondents, they obtained average results, and $18 \%$ had high results. The nurses working day shifts and those who perceived their health status as very good achieved considerably higher HBI results. The percentage of nurses with abnormal BMI was larger $(\mathrm{p}<0.0001)$ among those working rotating shifts. The nurses with higher BMI had lower perception of their health (Tab. 3.).

There were more alcohol users among rotating shift workers $(\mathrm{p}<0.0001)$, while smokers were more common among those working day shifts only $(\mathrm{p}<0.0001)$. Day shift workers less often reported pain complaints than their counterparts working rotating shifts - headache (71\%), back pain (92\%), and leg pain (93\%). Allergic skin diseases were observed in $12 \%$ of the nurses working day shifts, and in $35 \%$ of those involved in rotating shift work $(\mathrm{p}<0.0001)$ (Tab. 4.).

\section{DISCUSSION}

A rotating day/night shift work system puts strain on the body and disturbs the functioning of defense mechanisms. Exposure to negative factors may contribute to a higher incidence of health problems [3-18].

In the study of Muszalik et al. [5], 65.9\% of the nurses described their health status as good or very good, despite the fact that they worked in unfavorable environment. These results were confirmed by our findings, showing that as many as $76 \%$ of the surveyed regarded their health status as good or very good.

One of the major problems faced by shift workers is improper body weight. Copertaro et al. [6] analyzed a group of nurses of both sexes, finding that BMI $>25$ was more common in rotating shift workers than nurses working day shifts only. The difference in incidences of overweight and obesity between both groups was $12 \%$. Similar results were reported by Zhao et al. [7], who reported a higher risk of weight gain leading to overweight and obesity in nurses and midwives doing shift work. The relationship between eating disorders and a work system was analyzed by Karlsson's team [8], who noticed a statistically significant relationship between obesity and working shifts. Also our results indicate that higher average BMI results occur in people doing shift work.

Geliebter et al. [9] observed that the nurses only involved in day work had lower weight gain $(0.7 \mathrm{~kg}$ vs. $4.4 \mathrm{~kg}$ : $\mathrm{p}<0.008)$ than those working day/night shifts.

Marqueze et al. analyzed a group of 446 nurses and auxiliary nurses working according to a day/night shift pattern. These authors provided evidence for an increase in body weight in the nurses working rotating shifts [10], what corresponds with our results showing that such nurses had higher BMI.

Dai et al. [11] observed a statistically significant relationship $(\mathrm{p}<0.05)$ between sleep disorders and a shift work system. In the study conducted by Booker's team
[12], 20-30\% of the individuals working at night suffered from excessive drowsiness during a day combined with sleep disorders. Similarly, Leger et al. [13] demonstrated that people working day/night shifts struggled with insomnia, drowsiness, and shorter sleep time per day. The causes of such disorders are assigned to dysregulation of circadian clock. A greater risk of sleep disorders for shift workers was also reported by Books et al. [14]. In our study, sleep disorders were observed in $68 \%$ of the shift workers.

Another subject of researchers' interest is the contribution of shift work to the occurrence of pain complaints. In Muszalik et al.s study [5], such problems taking the form of headaches and back pains were faced by a vast majority of the nurses irrespective of their work system. According to Anbazhagan et al. [16], shift work is related to a number of disorders, including headaches and back pains, observed in $60.0 \%$ and $57.6 \%$ of shift workers, respectively. Zhao et al. [7] informed that the risk of pain in the lumbar spine was significantly statistically higher for people working rotating shifts $(\mathrm{p}<0.03)$ than for those working day shifts only. Our results show that also headaches and back pains are more common in nurses doing rotating shift work.

As stated by Sińska et al. [18], over half of the shift workers described their diet as bad compared with $30 \%$ of those working day shifts. Our findings indicate that an average result for good eating habits $-3.88(S D=0.42)$ was higher for the individuals working day shifts.

Adverse effects of shift work are important health care issues. It is reasonable to carry out further research in order to identify all potentially detrimental factors, and to ensure safety working conditions for nursing staff.

\section{CONCLUSIONS}

1. A work system had substantial effect on self-reported health status of the studied group of nurses.

2. The nurses working day shifts displayed a higher level of health behaviors than their counterparts working in a shift system.

3. A day/night shift work pattern correlated with a higher incidence of eating disorders. 


\section{Wpływ pracy zmianowej na zachowania zdrowotne i samoocenę zdrowia pielęgniarek}

\section{WPROWADZENIE}

Zawody medyczne ze względu na specyficzny charakter wykonywanej pracy wiążą się z narażeniem na czynniki negatywnie wpływające na stan zdrowia jednostki. Spośród nich można wymienić czynniki: biologiczne (drobnoustroje chorobotwórcze), fizyczne (pole elektromagnetyczne, promieniowanie jonizujące, laserowe, ultrafioletowe), chemiczne (gazy anestetyczne, środki dezynfekcyjne, leki cytostatyczne, lateks), ergonomiczne (dostęp do specjalistycznego sprzętu, nadmierny wysiłek fizyczny, niewłaściwa organizacja stanowiska pracy, lekceważenie przez pracowników niepokojących dolegliwości), psychiczne (stres, organizacja i warunki pracy, rodzaj zadań, zasoby instytucji wpływające na komfort pracy) oraz związane z wpływem mikroklimatu na organizm (mikroklimat zimny lub gorący, hałas, wibracje) [1]. Oddziaływanie tych elementów może prowadzić do powstania niepożądanych konsekwencji zdrowotnych u pracowników. Konieczność zapewnienia ciągłości opieki hospitalizowanym pacjentom wiąże się z potrzebą wprowadzenia zmianowego systemu pracy. System, w którym występują naprzemiennie zmiany nocne oraz dzienne trwające dwanaście godzin jest podstawową formą zatrudnienia personelu pielęgniarskiego [2]. W literaturze przedmiotu przedstawiane są liczne doniesienia wskazujące na niekorzystny wpływ pracy zmianowej na organizm ludzki, który zwiększa ryzyko wystąpienia schorzeń układu krążenia, układu pokarmowego, zaburzeń snu, zaburzeń neuropsychiatrycznych oraz dolegliwości bólowych [3-17]. Negatywne czynniki środowiskowe i zmianowy system pracy mogą również znacząco wpływać na stan zdrowia personelu pielęgniarskiego.

\section{CEL PRACY}

Celem przeprowadzonych badań była analiza wpływu pracy zmianowej na samoocenę zdrowia oraz zachowania zdrowotne pielęgniarek.

\section{MATERIAŁ I METODYKA}

Grupę badaną stanowiło 200 pielęgniarek i pielęgniarzy zatrudnionych w trzech szczecińskich placówkach ochrony zdrowia - Samodzielny Publiczny Szpital Kliniczny Nr 1 Pomorskiego Uniwersytetu Medycznego w Szczecinie, Samodzielny Publiczny Szpital Kliniczny $\mathrm{Nr} 2$ Pomorskiego Uniwersytetu Medycznego w Szczecinie oraz Samodzielny Publiczny Wojewódzki Szpital Zespolony. Personel pielęgniarski objęty badaniem pracował w oddziałach: intensywnej terapii, kardiologii, chirurgii, gastroenterologii, neurologii, ginekologii, pediatrii, onkologii, nefrologii, hematologii, bloku operacyjnym, szpitalnym oddziale ratunkowym oraz izbie przyjęć.
Badania przeprowadzono metodą sondażu diagnostycznego przy użyciu autorskiego kwestionariusza ankiety, który służył do badania sytuacji socjodemograficznej i medycznej, oraz standaryzowanego kwestionariusza do oceny zachowań zdrowotnych - Inwentarza Zachowań Zdrowotnych (IZZ) autorstwa Zygfryda Juczyńskiego [17]. Narzędzie to składa się z 24 stwierdzeń opisujących cztery kategorie zdrowotne: prawidłowe nawyki żywieniowe, praktyki zdrowotne, zachowania profilaktyczne oraz pozytywne nastawienie psychiczne. Prawidłowe nawyki żywieniowe dotyczą spożywania zdrowej żywności. Zachowania profilaktyczne obejmują pozyskiwanie informacji na temat zdrowia i choroby oraz przestrzegania zaleceń. Praktyki zdrowotne dotyczą rekreacji, snu oraz uprawiania aktywności fizycznej. Pozytywne nastawienie psychiczne obejmuje zachowania dotyczące unikania stresów, silnych emocji oraz napięć. Ogólny wskaźnik nasilenia zachowań zdrowotnych mieści się w granicach $24-120$ punktów. Im wyższy wynik tym większe nasilenie zachowań zdrowotnych. Otrzymane wyniki badań poddano analizie statystycznej z zastosowaniem następujących testów: współczynnik korelacji r-Pearsona, analizę wariancji Fischera - Snedecora, test Chi - kwadrat Pearsona. Do sporządzenia interpretacji statystycznej danych wykorzystano program IBM SPSS w wersji 22.

\section{WYNIKI}

Zdecydowaną większość wśród ankietowanych, tj. 97\% stanowily kobiety, ponad połowa badanych (55\%) to osoby w wieku od 30-60 lat. Większość badanych, tj. $71,1 \%$ pracowała w systemie zmianowym dwunastogodzinnym. W badanej grupie przeważały osoby o prawidłowej masie ciała (63\%), z kolei u 34\% wskaźnik BMI przekraczał normę a niedowaga występowała u 3\% respondentów.

Większość (93\%) stanowiły osoby aktywne fizycznie, tylko 7\% respondentów deklarowało, że nie uprawia sportu, bądź nie podejmuje żadnej aktywności fizycznej. Ryzykowne zachowania podejmowane przez badanych to spożywanie alkoholu (85\%) oraz palenie tytoniu (61\%).

Samoocena zdrowia pielęgniarek plasowała się na wysokim poziomie, aż $76 \% \mathrm{z}$ nich określiło swój stan zdrowia jako dobry lub bardzo dobry. Wśród przyczyn problemów zdrowotnych ankietowani wymieniali: stres (35\%), wypadki losowe (15\%), pracę (11\%), sposób odżywiania (7\%) $\mathrm{i}$ inne (9\%).

Problemy zdrowotne związane $\mathrm{z}$ wykonywaną pracą deklarowało 36\% personelu. Wśród najczęściej wymienianych dolegliwości były: zaburzenia snu (55\%), napady bólów głowy po powrocie z pracy (55\%), rozdrażnienie po powrocie z pracy $(83 \%)$, problemy skórne $(28 \%)$, bóle 
kręgosłupa (76\%), ból/zmęczenie nóg (84\%), zaburzenia laknienia (14\%).

Personel medyczny pracujący w systemie dziennym zdecydowanie lepiej oceniał swój stan zdrowia w porównaniu $\mathrm{z}$ osobami zatrudnionymi w zmianowym systemie pracy $(\mathrm{p}<0,0001)$ (Tab. 1). Samoocena zdrowia uzale $\dot{z}-$ niona była również od miejsca zatrudnienia, gdyż najwyższą wykazano u osób zatrudnionych w oddziałach onkologii, hematologii oraz izbie przyjęć, a najniższą na oddziałach intensywnej terapii oraz gastroenterologii (Tab. 2).

Ocena wyników zachowań prozdrowotnych dokonana za pomocą IZZ wykazała, że większość badanych, tj. 54\% charakteryzowała się niskim nasileniem zachowań sprzyjających zdrowiu. Wynik na poziomie przeciętnym uzyskało - $28 \%$ pielęgniarek, a wysoki - $18 \%$. Osoby pracujące w dziennym systemie pracy cechowały się dużo wyższym wskaźnikiem zachowań zdrowotnych, również osoby które oceniły swój stan jako bardzo dobry uzyskały wyższe wyniki w skali IZZ. Wśród osób zatrudnionych w systemie pracy zmianowej występował większy odsetek osób z nieprawidłową wartością wskaźnika BMI ( $\mathrm{p}<0,0001)$. Personel o wyższym poziomie współczynnika masy ciała gorzej oceniał także stan swojego zdrowia (Tab. 3).

Osoby zatrudnione w systemie zmianowym częściej sięgały po alkohol $(\mathrm{p}<0,0001)$, natomiast po tytoń personel pracujący w systemie dziennym $(\mathrm{p}<0,0001)$. Pielęgniarki zatrudnione w systemie dziennym rzadziej zgłaszały dolegliwości w porównaniu do personelu pracującego w systemie zmianowym, który wskazywał na występowanie dolegliwości bólowych: głowy (71\%), kręgosłupa (92\%) i nóg (93\%). Choroby alergiczne skóry występowały u $12 \%$ osób pracujących w systemie dziennym i u 35\% pracujących w systemie zmianowym $(\mathrm{p}<0,0001)$ (Tab. 4).

\section{DYSKUSJA}

Zatrudnienie w systemie zmianowym, który obejmuje również pracę w godzinach nocnych wpływa obciążająco na organizm powodując zaburzenia jego mechanizmów obronnych. Narażenie osłabionego organizmu na działanie negatywnych czynników może przyczynić się do częstszego występowania dolegliwości zdrowotnych [3-18].

Badania przeprowadzone przez Muszalik i wsp. [5] pokazały, że $65,9 \%$ pielęgniarek oceniło swój stan zdrowia jako dobry lub bardzo dobry, pomimo pracy w środowisku wpływającym obciążająco na organizm. Potwierdzeniem badań tych autorów są wyniki własne w których, aż $76 \%$ ankietowanych określiło swój stan zdrowia na poziomie dobrym i bardzo dobrym.

Istotnym problemem dotyczącym osób zatrudnionych w systemie zmianowym jest występowanie nieprawidłowej masy ciała. Copertaro i wsp. [6] w grupie badanych pielęgniarzy i pielęgniarek wykazali, że wskaźnik BMI przekraczający 25 częściej występował u osób pracujących w systemie zmianowym. Różnica między częstością występowania nadwagi i otyłości w obu grupach wynosiła $12 \%$. Zbliżone wyniki uzyskał zespół Zhao [7] potwierdzając występowanie wyższego ryzyka wzrostu masy ciała prowadzącego do nadwagi i otyłości u pielęgniarek i położnych pracujących w systemie zmianowym. Zależności pomiędzy występowaniem zaburzeń odżywiania a systemem pracy były również przedmiotem badania zespołu Karlsson'a [8]. W badaniach tych zauważono istotną statystycznie zależność pomiędzy występowaniem otyłości, a pracą w systemie zmianowym. Wyniki badań własnych również wskazują na występowanie wyższych średnich wartości wskaźnika BMI u osób zatrudnionych w zmianowym systemie pracy.

Zespół Geliebter [9] zaobserwował, że u osób pracujących wyłącznie w ciągu dnia występuje niższy przyrost masy ciała $(0,7 \mathrm{~kg}$ vs $4,4 \mathrm{~kg}$ : $\mathrm{p}<0,008)$ w stosunku do pielęgniarek pracujących w systemie zmianowym.

Marqueze i wsp. przeprowadzili badania w grupie 446 osób zatrudnionych na stanowisku pielęgniarki oraz pomocy pielęgniarskiej w systemie dziennym i nocnym. Autorzy dowiedli, że wyższy przyrost masy ciała występował u osób pracujących w systemie zmianowym [10]. Powyższe wyniki są porównywalne $z$ badaniami własnymi w których obserwowano wyższy wskaźnik BMI u pielęgniarek zatrudnionych w systemie zmianowym.

Dai i wsp. [11] zaobserwowali istotną statystycznie $(\mathrm{p}<0,05)$ zależność pomiędzy występowaniem zaburzeń snu a pracą w systemie zmianowym. Badania zespołu Booker'a [12] pokazały, że u 20-30\% osób pracujących w godzinach nocnych występuje nadmierna senność w ciągu dnia połączona z zaburzeniami snu w ciągu nocy. $\mathrm{Z}$ kolei Leger i wsp. [13] wykazał, że u osób zatrudnionych $\mathrm{w}$ systemie zmianowym poważnym problemem jest bezsenność, ospałość oraz skrócenie czasu snu w ciągu doby. Konsekwencji tego typu zaburzeń badacze dopatrują się w rozregulowaniu zegara biologicznego człowieka. Wzrost ryzyka wystąpienia zaburzeń snu u osób zatrudnionych w zmianowym systemie pracy wykazał także zespół Books’a [14]. W badaniach własnych zaburzenia snu u osób pracujących w systemie zmianowym wykazano u $68 \%$.

Przedmiotem zainteresowania badaczy był również wpływ pracy w systemie zmianowym na występowanie dolegliwości bólowych. Zespół Muszalik [5] wykazał, że dolegliwości pod postacią bólu głowy i kręgosłupa występowały u zdecydowanej większości pielęgniarek niezależnie od systemu pracy. Anbazhagan i wsp. [16] określił związek szeregu zaburzeń z pracą w systemie zmianowym. Należały do nich m.in dolegliwości bólowe głowy i pleców, które występowały odpowiednio u 60,0\% i 57,6\% osób pracujących w systemie zmianowym. Zhao wraz z zespołem [7] wykazał, że u osób pracujących w systemie zmianowym ryzyko wystąpienia dolegliwości bólowych dolnego odcinka kręgosłupa było istotnie statystycznie większe $(\mathrm{p}<0,03)$ w porównaniu $\mathrm{z}$ grupą osób zatrudnionych w systemie dziennym. Wyniki badań własnych wskazują również na częstsze występowanie dolegliwości bólowych głowy i kręgosłupa u osób pracujących w systemie zmianowym.

Badania Sińskiej i wsp. [18] wykazały, że ponad połowa osób zatrudnionych w systemie zmianowym określiła swój sposób odżywiania, jako nieprawidłowy w porównaniu do 30\% osób zatrudnionych w systemie dziennym. Wyniki badań własnych wskazują, że wyższą średnią wartość w zakresie prawidłowych nawyków żywieniowych 
Tab. 1. Wpływ systemu pracy na samoocenę zdrowia pielęgniarek

\begin{tabular}{|c|c|c|c|c|c|c|c|c|c|c|}
\hline \multirow{3}{*}{ System pracy } & \multicolumn{8}{|c|}{ Subiektywna ocena stanu zdrowia } & \multirow{3}{*}{$\lambda^{2}$} & \multirow{3}{*}{$\mathbf{p}$} \\
\hline & \multicolumn{2}{|c|}{$\begin{array}{l}\text { bardzo } \\
\text { dobry }\end{array}$} & \multicolumn{2}{|c|}{ dobry } & \multicolumn{2}{|c|}{ normalny } & \multicolumn{2}{|c|}{ mierny } & & \\
\hline & $\mathbf{n}$ & $\%$ & $\mathbf{n}$ & $\%$ & $\mathbf{n}$ & $\%$ & $\mathbf{n}$ & $\%$ & & \\
\hline Dzienny & 44 & 76 & 12 & 21 & 2 & 3 & 0 & 0 & 90,97 & 0,000 \\
\hline Zmianowy & 13 & 9 & 84 & 59 & 44 & 31 & 1 & 1 & 90,97 & 0,000 \\
\hline
\end{tabular}

$\mathrm{n}$ - liczebność, $\lambda^{2}$ - test Chi - kwadrat Pearsona, p - współczynnik istotności statystycznej

Tab. 2. Współczynnik korelacji między wskaźnikiem nasilenia zachowań zdrowotnych a miejscem zatrudnienia pielęgniarek

\begin{tabular}{|l|c|c|c|c|c|}
\hline \multicolumn{1}{|c|}{ Oddział } & $\mathbf{n}$ & $\mathbf{M} \pm$ SD & Min - Max & F & p \\
\hline Izba przyjęć & 10 & $5,70-2,35$ & $1-8$ & & \\
\hline Gastroenterologia & 14 & $5,35-2,43$ & $2-10$ & & \\
\hline Pediatria & 10 & $5,30-1,70$ & $2-7$ & & \\
\hline Onkologia & 10 & $5,10-2,42$ & $1-8$ & & \\
\hline Hematologia & 6 & $5,00-1,54$ & $2-6$ & & \\
\hline SOR & 13 & $4,76-2,16$ & $1-8$ & & \multirow{2}{*}{0,002} \\
\hline Blok operacyjny & 12 & $4,75-2,05$ & $1-7$ & \\
\cline { 1 - 4 } Neurologia & 11 & $4,63-2,46$ & $1-8$ & & \\
\hline Kardiologia & 19 & $4,52-2,09$ & $1-8$ & & \\
\hline Ginekologia & 11 & $4,36-2,11$ & $2-7$ & & \\
\hline Nefrologia & 9 & $4,33-2,00$ & $2-8$ & & \\
\hline Chirurgia & 18 & $3,88-2,32$ & $2-10$ & & \\
\hline Intensywna terapia & 57 & $3,21-1,48$ & $1-7$ & & \\
\hline
\end{tabular}

n - liczebność, M - średnia, SD -odchylenie standardowe, Max -maksimum, Min - minimum,

F - test Fishera - Snedecora, p - współczynnik istotności statystycznej
Tab. 3. Współczynnik korelacji między wskaźnikiem nasilenia zachowań zdrowotnych a BMI i systemem pracy pielęgniarek

\begin{tabular}{|c|c|c|c|c|c|c|}
\hline \begin{tabular}{|c|} 
Kategorie \\
zachowań \\
zdrowotnych \\
według \\
kwestionariusza \\
IZZ \\
\end{tabular} & $\begin{array}{l}\text { System } \\
\text { pracy }\end{array}$ & $\mathbf{n}$ & $M \pm S D$ & Min - Max & $\mathbf{F}$ & p \\
\hline \multirow{3}{*}{$\begin{array}{l}\text { Prawidłowe } \\
\text { nawyki } \\
\text { żywieniowe }\end{array}$} & Dzienny & 58 & $3,88-0,42$ & $2,50-4,83$ & \multirow{3}{*}{55,40} & \multirow{3}{*}{0,000} \\
\hline & Zmianowy & 142 & $3,12-0,74$ & $1,67-4,67$ & & \\
\hline & Razem & 200 & $3,34-0,74$ & $1,67-4,83$ & & \\
\hline \multirow{3}{*}{$\begin{array}{l}\text { Zachowania } \\
\text { profilaktyczne }\end{array}$} & Dzienny & 58 & $3,42-0,35$ & $2,33-4,83$ & \multirow{3}{*}{36,64} & \multirow{3}{*}{0,0001} \\
\hline & Zmianowy & 142 & $3,83-0,71$ & $1,17-5,00$ & & \\
\hline & Razem & 200 & $3,00-0,68$ & $1,17-5,00$ & & \\
\hline \multirow{3}{*}{\begin{tabular}{|l} 
Pozytywne \\
nastawienie \\
psychiczne
\end{tabular}} & Dzienny & 58 & $3,99-0,50$ & $2,33-4,83$ & \multirow{3}{*}{82,55} & \multirow{3}{*}{0,0001} \\
\hline & Zmianowy & 142 & $3,08-0,70$ & $1,83-5,00$ & & \\
\hline & Razem & 200 & $3,35-0,77$ & $1,83-5,00$ & & \\
\hline \multirow{3}{*}{$\begin{array}{l}\text { Praktyki } \\
\text { zdrowotne }\end{array}$} & Dzienny & 58 & $4,02-0,38$ & $3,00-4,83$ & \multirow{3}{*}{312,36} & \multirow{3}{*}{0,0001} \\
\hline & Zmianowy & 142 & $2,42-0,64$ & $1,17-4,67$ & & \\
\hline & Razem & 200 & $2,88-0,93$ & $1,17-4,83$ & & \\
\hline \multirow{3}{*}{\begin{tabular}{|l|} 
Ogólny wskaźnik \\
nasilenia \\
zachowań \\
zdrowotnych (IZZ) \\
\end{tabular}} & Dzienny & 58 & $6,55-1,01$ & $5-10$ & \multirow{3}{*}{171,38} & \multirow{3}{*}{0,0001} \\
\hline & Zmianowy & 142 & $3,39-1,72$ & $1-10$ & & \\
\hline & Razem & 200 & $4,31-2,11$ & $1-10$ & & \\
\hline \multirow{3}{*}{ Wskaźnik BMI } & Dzienny & 58 & $23,01-4,21$ & $17,91-39,18$ & \multirow{3}{*}{171,38} & \multirow{3}{*}{0,000} \\
\hline & Zmianowy & 142 & $24,51-4,30$ & $18,82-39,18$ & & \\
\hline & Razem & 200 & $24,07-4,31$ & $17,91-39,18$ & & \\
\hline
\end{tabular}

$\mathrm{n}$ - liczebność, Min - minimum, Max - maksimum, M - średnia, SD -odchylenie standardowe, F - tes Fishera - Snedecora, p - współczynnik istotności statystycznej, IZZ - Inwentarz zachowań zdrowotnych

Tab. 4. Wpływ systemu pracy na występowanie zachowań ryzykownych/dolegliwości u pielęgniarek

\begin{tabular}{|c|c|c|c|c|c|c|c|c|c|c|c|c|c|}
\hline \multirow{3}{*}{$\begin{array}{l}\text { Zachowania zdrowotne } \\
\text { /Zgłaszane dolegliwości }\end{array}$} & \multirow{3}{*}{ System pracy } & \multicolumn{10}{|c|}{ Występowanie zachowań ryzykownych/dolegliwości } & \multirow{3}{*}{$\lambda^{2}$} & \multirow{3}{*}{$\mathbf{p}$} \\
\hline & & \multicolumn{2}{|c|}{ wcale } & \multicolumn{2}{|c|}{$\begin{array}{c}\text { rzadziej niż raz } \\
\text { w tygodniu }\end{array}$} & \multicolumn{2}{|c|}{ raz w tygodniu } & \multicolumn{2}{|c|}{$\begin{array}{c}\text { do trzech razy w } \\
\text { tygodniu }\end{array}$} & \multicolumn{2}{|c|}{$\begin{array}{l}\text { powyżej trzech } \\
\text { razy w tygodniu }\end{array}$} & & \\
\hline & & $\mathbf{n}$ & $\%$ & $\mathbf{n}$ & $\%$ & $\mathbf{n}$ & $\%$ & $\mathbf{n}$ & $\%$ & $\mathbf{n}$ & $\%$ & & \\
\hline \multirow{2}{*}{ Spożywanie alkoholu } & Dzienny & 27 & 19 & 99 & 70 & 9 & 6 & 6 & 4 & 2 & 1 & \multirow{2}{*}{56,33} & \multirow{2}{*}{0,000} \\
\hline & Zmianowy & 2 & 3 & 26 & 45 & 29 & 50 & 1 & 2 & 0 & 0 & & \\
\hline & & \multicolumn{2}{|c|}{ wcale } & \multicolumn{2}{|c|}{ rzadko } & \multicolumn{2}{|c|}{ czasami } & \multicolumn{2}{|c|}{ raczej często } & \multicolumn{2}{|c|}{ bardzo często } & $\lambda^{2}$ & $\mathbf{p}$ \\
\hline \multirow{2}{*}{ Palenie tytoniu } & Dzienny & 30 & 52 & 24 & 41 & 3 & 5 & 1 & 2 & 0 & 0 & \multirow{2}{*}{53,58} & \multirow{10}{*}{0,000} \\
\hline & Zmianowy & 48 & 34 & 12 & 8 & 28 & 20 & 39 & 27 & 15 & 11 & & \\
\hline \multirow{2}{*}{ Problemy z zasypianiem } & Dzienny & 45 & 78 & 10 & 17 & 3 & 5 & 0 & 0 & 0 & 0 & \multirow{2}{*}{37,67} & \\
\hline & Zmianowy & 45 & 32 & 44 & 31 & 37 & 26 & 15 & 11 & 1 & 1 & & \\
\hline \multirow{2}{*}{$\begin{array}{l}\text { Dolegliwości bólowe } \\
\text { głowy }\end{array}$} & Dzienny & 50 & 86 & 6 & 10 & 1 & 2 & 1 & 2 & 0 & 0 & \multirow{2}{*}{56,17} & \\
\hline & Zmianowy & 41 & 29 & 37 & 26 & 47 & 33 & 16 & 11 & 1 & 1 & & \\
\hline \multirow{2}{*}{$\begin{array}{l}\text { Dolegliwości bólowe } \\
\text { kręgosłupa }\end{array}$} & Dzienny & 37 & 64 & 10 & 17 & 9 & 16 & 2 & 3 & 0 & 0 & \multirow{2}{*}{76,79} & \\
\hline & Zmianowy & 11 & 8 & 27 & 19 & 58 & 41 & 18 & 13 & 28 & 20 & & \\
\hline \multirow{2}{*}{$\begin{array}{l}\text { Zmęczenie, dolegliwości } \\
\text { bólowe nóg }\end{array}$} & Dzienny & 22 & 38 & 27 & 47 & 8 & 14 & 0 & 0 & 1 & 2 & \multirow{2}{*}{69,80} & \\
\hline & Zmianowy & 10 & 7 & 21 & 15 & 68 & 48 & 18 & 13 & 25 & 18 & & \\
\hline & & \multicolumn{6}{|c|}{ Tak } & \multicolumn{4}{|c|}{ Nie } & \multirow{2}{*}{$\lambda^{2}$} & \\
\hline & & & $\mathbf{n}$ & & & $\%$ & & & & & & & P \\
\hline & Dzienny & & 7 & & & 12 & & & & & & & \\
\hline Chlorody dergicane & Zmianowy & & 49 & & & 35 & & & & & & 10,20 & 0,000 \\
\hline
\end{tabular}

$\mathrm{n}$ - liczebność, \% - procent, $\lambda^{2}$ - test Chi - kwadrat Pearsona, p - współczynnik istotności statystycznej 
wynoszącą 3,88 (SD=0,42) uzyskały osoby pracujące w dziennym systemie pracy.

Zagadnienia dotyczące negatywnych skutków pracy w systemie zmianowym to ważny obszar ochrony zdrowia. Wskazane są dalsze badania w kierunku zapewnienia bezpiecznych warunków pracy personelu pielęgniarskiego oraz identyfikacji wszystkich czynników stanowiących potencjalne zagrożenie.

\section{WNIOSKI}

1. System pracy znacząco wpływa na poziom samooceny zdrowia badanej grupy pielęgniarek.

2. Personel pielęgniarski pracujący w dziennym systemie pracy cechował się wyższym poziomem zachowań zdrowotnych w porównaniu do pielęgniarek pracujących w systemie zmianowym.

3. Praca w systemie zmianowym korelowała $\mathrm{z}$ częstszym wystąpieniem zaburzeń odżywiania w porównaniu do zatrudnienia w systemie dziennym.

\section{REFERENCES/PIŚMIENNICTWO}

1. Świątkowska B. Zagrożenia zawodowe pracowników opieki zdrowotnej: Co wiemy co możemy zrobić? Probl hig epidemiol. 2010;4 (91): 522-529.

2. Wrońska I, Krajewska-Kułak E. Wybrane zagadnienia z pielęgniarstwa Europejskiego. Lublin: Czelej; 2007, s.157-202.

3. Havakuk 0, et al. Shift Work and the Risk of Coronary Artery Disease: A Cardiac Computed Tomography Angiography Study. Cardiology. 2018;1 (139): 11-16.

4. Bilski B. Wpływ pracy zmianowej na sposób odżywiania się i patologię przewodu pokarmowego wśród pielęgniarek - wyniki badania pilotowego. Medycyna pracy. 2006;1 (57): 15-19.

5. Muszalik M, Kędziora-Kornatowska K, Marzec A, Klawe J. Analiza zachowań zdrowotnych, samooceny oraz zagrożenia zdrowia pielęgniarek studiujących zaocznie. Probl. High Epidemiol. 2007;3 (88): 354-359.

6. Copertaro A, Bracci M, Barbaresi M, Santarelli L. Assessment of cardiovascular risk in shift healthcare workers. Eur. J. Cardiovasc. Prev. Rehabil. 2008;2 (15): 224-229.

7. Zhao I, Bogossian F, Turner C. A cross-sectional analysis of the association between night-only or rotating shift work and overweight/obesity among female nurses and midwives. J Occup. Environ. Med. 2012;7 (54): 834-840.

8. Karlsson B, Knutsson A, Lindahl B. Is there an association between shift work and having a metabolic syndrome? Results from a population based study of 27,485 people. Occup Environ Med. 2001;58: 747-752.

9. Geliebter A, et al. Work'chift period and weigh change. Nutrition. 2000;1 (16): 27-29.

10. Marqueze EC, et al. Weight gain in relation to night work among nurses. Work. 2012;1 (14): 2043-2048.

11. Dai $C$, et al. The effect of night shift on sleep quality and depressive symptoms among Chinese nurses. Neuropsychiatr Dis Treat. 2019;15: 435-440.

12. Booker $L A$, et al. Individual vulnerability to insomnia, excessive sleepiness and shift work disorder amongst healthcare shift workers. A systematic review. Sleep Med Rev. 2018;41: 220-233.

13. Leger D, Esquirol Y, Gronfier C, Metlaine A. Shift-workers and night-workers' health consequences: State of art and recommendations Presse Med. 2018;1 (47): 991-999.

14. Books C, Coody LC, Kauffman R, Abraham S. Night Shift Work and Its Health Effects on Nurses. Health Care Manag (Frederick). 2017; 4 (36): 347-353.

15. Lee A, et al. Night Shift Work and Risk of Depression: Meta-analysis of Observational Studies. J Korean Med Sci. 2017;7 (32): 1091-1096.

16. Anbazhagan S, Ramesh N, Nisha C, Joseph B. Shift work disorder and related health problems among nurses working in a tertiary care hospital, Bangalore, South India. Indian J Occup Environ Med. 2016;1 (20): 35-38.

17. Juczyński Z. Narzędzia pomiaru w promocji i psychologii zdrowia. Warszawa: Pracownia Testów Psychologicznych; 2009, s.115.

18. Sińska B, Kucharska A, Sienkiewicz Z, Dykowska G. Wpływ systemu zmianowego pracy pielęgniarek na ich sposób odżywiania i aktywność fizyczną. Zdrowie publiczne i zarządzanie. 2018;2 (16): 105-111..

Manuscript received/Praca zgłoszona do czasopisma: 26.09.2018

Manuscript accepted/Praca zaakceptowana do druku: 15.03.2019

Translation/Tłumaczenie: Barbara Kamienowska 